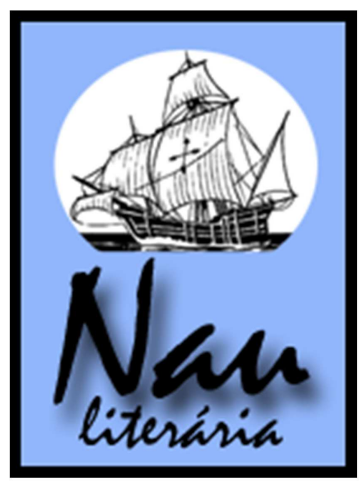

\title{
Tradição e memória: as guardiãs da Praia do Bispo e do Sobrado de Santa Fé
}

\section{Laurene Veras}

\begin{abstract}
Resumo: O artigo propõe uma reflexão sobre o papel das mulheres nas questões relativas à memória, tradição e identidade das coletividades representadas pela família, comunidade e/ou nação, realizando um cotejo entre as matriarcas de AvóDezanove $e$ o segredo do Soviético, de Ondjaki, e as matriarcas do Sobrado em $O$ tempo e o vento de Erico Verissimo.
\end{abstract}

Palavras-chave: Tradição; Memória; Mito; Conquista; Preservação.

\begin{abstract}
The article analyses a reflection about the women's part in memory, tradition and identity questions related to collectivitys that are represented by family, comunity and/or nation, doing a parallel between the matriarchs of Ondjaki's AvóDezanove e o segredo do soviético, and the matriarchs of the Erico Verissimo's $O$ tempo e o vento.
\end{abstract}

Keywords: Tradition; Memory; Myth; Conquest; Preservation.

A escrita adotada por Ondjaki em AvóDezanove e o segredo do soviético tem um tom memorialístico, assim como Bom dia camaradas e Os da minha rua, formando uma espécie de trilogia. Entretanto, além da estória em primeira pessoa contada pelo narrador - menino há também a história implícita no texto que recorda. Isto é o que Jan Assmann (2003) chama de mnemohistória, a história que "It surveys the story-lines of tradition, the webs of intertextuality, the diachronic continuities and descontinuities of reading the past ${ }^{1}$ ". Segundo ASSMANN (2007), em seus estudos sobre "memória cultural", existem duas importantes subcategorias de memória, assim definidas: "El pasado que se recuerda es una cosa distinta al pasado que se investiga. El pasado que se recuerda tiene un carácter apelativo, una cualidad "mito - motora.". 2 Tanto o passado afetivo quanto o passado histórico aparecem no texto literário, mas a nós interessa verificar de que modo estes dois tipos distintos de memória aparecem e como acabam se relacionando no corpo da narrativa.

Tomadas estas definições de Assmann como pressupostos teóricos para análise do texto de Ondjaki em AvóDezanove, veremos que a memória de toda uma comunidade,

\footnotetext{
* Mestranda no PPG-LET UFRGS em Literatura Portuguesa e Luso Africana, ênfase em Estudos Pós-Coloniais.

1 "Baseia-se nas estórias da tradição, nas redes de intertextualidade, na continuidade diacrônica e na descontinuidade da leitura do passado."

2 "O passado que se recorda é uma coisa distinta do passado que se investiga. O passado que recorda tem um caráter evocativo, uma qualidade 'mito-motora'."
} 
resgatada pelo narrador - menino é movida pela tradição oral e mítica através das personagens-testemunhas deste passado ${ }^{3}$, e através delas o passado que recorda, este passado que conta as entrelinhas da história através dos vínculos afetivos engendrados pela memória, é preservado e legitimado pela mnemohistória.

Ora, se nos basearmos no mesmo universo conceitual de Assmann, e nos transportarmos para uma cidade muito distante da Luanda de Ondjaki no tempo, espaço, e no limite entre ficção e realidade, teremos que a Santa Fé criada por Érico Verissimo em $O$ Tempo e o Vento pode apresentar uma relação dialógica com a cidade da contemporânea narrativa de Ondjaki. A despeito de uma aparente 'distância' existente entre as duas narrativas que estão sendo abordadas, a saber, o fato de Santa Fé ser fictícia e Luanda real, e Ondjaki ser um jovem escritor do século XXI enquanto Érico um grande representante da literatura do século XX, estas diferenças se tornam irrelevantes para o que se pretende aqui ao admitirmos duas hipóteses: a Luanda de que tratamos neste artigo é uma representação da Luanda real, logo, é parte do universo da ficção, uma Luanda fictícia recriada pelo olhar do narrador sobre a verdadeira Luanda; há que se levar em consideração o fato de que o romance enquanto porta voz das grandes questões que fazem parte da história da humanidade é atemporal, pois como afirma Vargas Llosa, "No embrião de todo romance ferve um inconformismo, pulsa um desejo insatisfeito." ${ }^{4}$ Nesse sentido o romance é além do tempo, na medida em que trata também de problemas universais concernentes ao papel do indivíduo na sociedade e ao conteúdo normativo inerente a toda narrativa.

Inserido no contexto de $O$ tempo e o vento, o "passado que recorda" tem tanta importância dentro da estrutura narrativa quanto o "passado que investiga" que é contado por Verissimo. É sabido que Érico Verissimo fez alguma pesquisa histórica para narrar a formação do Rio Grande do Sul, entretanto, é no âmbito da ficção que o autor faz questão de instaurar a complexidade da narrativa:

Um romancista é antes de tudo um intuitivo. Para $O$ Tempo e o Vento fiz o mínimo de pesquisas. Não me arrependo disso. É muito perigoso para o romance quando o autor sabe coisas demais sobre uma região ou uma época histórica. ${ }^{5}$

Em AvóDezanove e o segredo do soviético Ondjaki apresenta o mesmo narradormenino de Bom dia camaradas e Os da minha rua. Com o mesmo lirismo e o mesmo olhar

\footnotetext{
${ }^{3}$ Este artigo tratará especificamente de Avó Agnette e da Avó Catarina.

${ }^{4}$ LLOSA, Mario Vargas. A verdade das mentiras. São Paulo: Editora Arx, 2004, p.16.

5 “A agulha da bússola”. Entrevista concedida a Rosa Freire D’Aguiar. In: BORDINI, Maria da Glória (Org.). A liberdade de escrever - Erico Verissimo. Porto Alegre: Editora da Universidade/UFRGS/Edipucrs, Prefeitura Municipal de Porto Alegre. (Coleção Engenho e Arte; 4)
} 
infantil abordados nos dois livros anteriores, o narrador conta as aventuras de sua infância que se passam na Praia do Bispo, em Angola, onde estão os soviéticos que coordenam as obras do mausoléu de Agostinho Neto, popularmente chamado de 'Foguetão'. Na Praia do Bispo também vivem e trabalham os luandenses da região, tanto na obra do mausoléu quanto na pesca e em outras atividades relacionadas ao bairro, e é lá também que fica a casa que abriga o narrador, a casa da AvóAgnette, também chamada de AvóNhé e de AvóDezanove. A Praia do Bispo e a casa da Avó Agnette são os espaços da realidade ordinária e ao mesmo tempo do olhar transcendente que pertence à infância, ambos os espaços acrescidos de uma compreensão e memória em princípio muito mais intuitivas, e nesse sentido criativas, do que analíticas. Entretanto, permanece a percepção autor, que mesmo filtrando o mundo através das impressões do menino, ainda tece a estória que precisa ser contada, como descreve Jane Tutikian:

As lacunas da história, as zonas do esquecimento, são ditas de forma inocente, pelo olhar da criança, quase ao acaso, através da associação emotiva das imagens, entretanto, porque já passadas pelo crivo crítico do escritor, trazem consigo sinais de outros silêncios, os que precisam ser retirados do esquecimento para a memória comum, como ponte para uma história que não se pode perder, até porque integram o amadurecimento cultural que, por sua vez, integra os processos identitários. ${ }^{67}$

O ponto de vista que processa os acontecimentos e as lacunas históricas e subjetivas do narrador - menino faz uso de uma espécie de 'régua' não analítica. O olhar infantil que encontramos em Ondjaki é muito mais sensorial e sinestésico do que aridamente descritivo. Ondjaki se utiliza de uma linguagem predominantemente poética, o que transfigura a realidade em uma experiência feita de pequenos fragmentos de fantasia, como gritos que têm cores ${ }^{8}$ ou rastros de lesmas que têm sons ${ }^{9}$. Este universo narrativo onde à palavra importa mais o sensorial do que o puramente analítico define um estilo. A forma do texto de Ondjaki está entremeada pela linguagem da poesia e pela imaginação ampliada pelo prisma da infância.

\footnotetext{
${ }^{6}$ TUTIKIAN, Jane. Lá onde mora a infância (um estudo dos contos de Luandino Vieira e de Ondjaki). In: REMÉDIOS, Maria Luíza Ritzel; SILVEIRA, Regina da Costa (Org.). Redes e Capulanas: identidade, cultura e história nas literaturas lusófonas. Editora UniRitter: Porto Alegre, 2009. p. 107 - 123.

${ }^{7}$ Neste trecho do ensaio a autora se refere especificamente ao livro Os da minha rua, entretanto, admitindo-se a hipótese de que se trata de uma trilogia, a qual privilegia não apenas o mesmo espaço e o mesmo tempo histórico, mas também o mesmo narrador, as mesmas personagens e o mesmo tipo de linguagem, é lícito dizer que a análise da autora pode ser aplicada neste caso graças ao hipertexto presente em AvóDezanove que dialoga claramente com Os da minha rua. Além disso, a autora se refere ao olhar infantil, que é um dos principais pontos de contato entre as duas obras.

8 ONDJAKI, 2009, p.5

${ }^{9}$ ONDJAKI, 2009, p.36
} 
O tempo e o vento é narrado em primeira pessoa, mas diferente do narrador de Ondjaki, Floriano é um adulto que processa e conta os fatos mais objetivamente, fazendo uso de uma linguagem adequada à esta objetividade, o que não significa, é claro, que o texto de Verissimo careça de lirismo. Ao buscar os elementos do passado para a estória que quer contar, Floriano é conduzido pela mão da memória coletiva, a força "mito-motora" por trás da tradição mantida e guardada pelas matriarcas da família. Dito isto, assim como em AvóDezanove existem as matriarcas que tecem o fio da memória na tradição, também em $O$ tempo $e$ o vento elas desempenham um papel importante em relação ao "passado que recorda".

Avó Agnette $^{10}$ conduz o menino - narrador de Ondjaki pelas searas do tempo e instaura o espaço da memória coletiva que define o aspecto normativo da tradição e do mito:

-Estórias de antigamente é assim que já foram há muito

tempo?

- Sim, filho.

-Então antigamente é um tempo, Avó?

- Antigamente é um lugar.

- Um lugar assim longe?

- Um lugar assim dentro. (ONDJAKI, 2009, p.188)

A casa da Avó Agnette, tal qual o Sobrado no qual se passa a infância de Floriano, orientado pelo olhar atento da dinda Maria Valéria ${ }^{11}$, constitui o espaço da memória, o que vai ao encontro do que afirma Jane Tutikian: “Tempo e espaço se confundem, o espaço comprime o tempo. E a casa é o espaço da felicidade, do abrigo, da essência íntima e completa." 12

Quando Floriano Cambará necessita do "passado que recorda" para iniciar a pesquisa que vai servir de inspiração para o seu próximo romance, ele reconhece em Maria Valéria aquela que vai lhe emprestar o passado a ser narrado:

Quando a velha Maria Valéria anda pela casa nas suas rondas noturnas, com uma vela acesa na mão, vejo nela um farol. Estou certo de que a luz dessa vela me poderá alumiar alguns caminhos que ficaram para trás no tempo. [...] Tenho tentado, com algum sucesso, que a Dinda me conte "causos" de sua tia Bibiana, minha trisavó, e de seu marido, um certo Cap. Rodrigo, aventureiro, espadachim, mulherengo, homem de coragem extraordinária e apetites insaciáveis, desses que bebem a vida não aos copos, mas aos baldes. (VERISSIMO, 1963, p.747)

Maria Valéria não é somente a guardiã do clã Terra - Cambará, responsável por sua conservação e perpetuação, assim como também o foram Ana Terra e Bibiana. Ela também é

\footnotetext{
${ }^{10}$ Em AvóDezanove tratarei do mesmo modo AvóAgnette e Avó Catarina, pois são personagens complementares, duplos.

${ }^{11}$ Todas as mulheres que passam pelo Sobrado em $O$ Tempo $e$ o Vento têm importância fundamental e complexa no desenvolvimento do romance. Para este artigo ficaremos concentrados em Maria Valéria, pois é ela que alcança a longevidade necessária para dialogar diretamente com o narrador e ser a ponte entre ele e as guardiãs precedentes.

${ }^{12}$ Ibid.
} 
a chave para a memória que Floriano precisa acessar, e o resgate desta memória necessariamente há que buscar no tempo passado aquilo que no passado foi retido pela morte. Avó Agnette - ou AvóDezanove -, AvóCatarina e Maria Valéria são as cuidadoras da memória, dos vivos e dos mortos, e dos mitos e rituais necessários à conservação da ordem nestes dois universos. Em AvóDezanove, Avó Catarina é o próprio espectro da morte:

\begin{abstract}
Mesmo assim fui ralhado outra vez e a minha mãe até foi chamada à reunião de pais porque a camarada professora conhecia a família e disse que até era possível que um tio maluco tivesse enchido a piscina com coca-cola, mas o que era impossível era eu ter escrito que AvóCatarina podia ter ido nos acompanhar, porque a camarada professora sabia que a AvóCatarina já não vivia naquela casa há muitos anos.(ONDJAKI, 2009, p.74)
\end{abstract}

E o menino da Praia do Bispo intui sobre as artes secretas das avós, quando pergunta para AvóAgnette:

- Avó, tu não gostas de flores?

-Gosto, filho, mas gosto de as ver nos jardins, nas ruas, a dar cor à vida. A morte não tem cor nenhuma filho.

- A AvóCatarina também costuma dizer isso. (ONDJAKI, 2009, p.78)

Tanto as matriarcas de AvóDezanove quanto as de O tempo e o vento são conhecedoras dos caminhos e rituais da morte. AvóDezanove, por exemplo, é assim apelidada por ocasião de uma cirurgia, quando lhe é retirado um dedo do pé que está necrosado. Com a perda de um dedo, AvóAgnette passa a contar somente com dezenove dedos nos dois pés e passa a ser chamada de AvóDezanove. Entretanto, em vez de tratar a questão do dedo sem cerimônia, AvóNhé resolve dar uma festa, "a festa da despedida do dedo"13, o que configura um ritual pela perda de algo, um ritual fúnebre. A preocupação da AvóNhé com a importância dos ritos se confirma na página seguinte:

[...] AvóNhé perguntou se era preciso benzer ${ }^{14} \mathrm{o}$ dedo para a operação correr bem.

- Não, dona Agnette, ainda que fosse um dedo a nascer, fazia-se um pequeno batizado. Agora, assim, penso que esta festa será suficiente. O importante é que esteja bem-disposta. (ONDJAKI, 2009, 67)

No dia da cirurgia, a caminho do hospital, AvóAgnette pede para passar no cemitério e ver o túmulo do marido. É um dia de perda, e toda perda evoca os mortos, o luto e os ritos fúnebres.

As matriarcas de Erico Verissimo, em seus papéis de guardiãs dos vivos e da memória dos mortos da família, também evocam a morte em diversas ocasiões, como quando em noites de vento repetem o velho refrão iniciado por uma mitologia inaugurada por Ana Terra -

\footnotetext{
${ }^{13}$ ONDJAKI, 2009, p.66.

${ }^{14}$ Grifo meu.
} 
"Sempre que me acontece alguma coisa importante, está ventando" ${ }^{15}$-, passado a Bibiana e Maria Valéria e sempre repetido como uma antiga ladainha: “ - Bem dizia a minha avó resmunga D. Bibiana , cerrando os olhos. - "Noite de vento, noite dos mortos."16

Maria Valéria, a última das 'cuidadoras' dos Terra - Cambará, também tem seus rituais, assim como AvóNhé. Ao perceber que aos poucos a família se fragmenta e dissolve, ao final do segundo tomo de O RETRATO, chama o afilhado Floriano para que lhe acompanhe até o quintal enquanto carrega uma vela:

Fizeram alto perto do marmeleiro-da-índia. Maria Valéria tirou o toco de vela do castiçal, inclinou-se e cravou-o no chão.

- Pra que é isso? - perguntou Floriano.

- Uma promessa pro Negrinho do Pastoreio.

A velha endireitou o corpo e fez com a cabeça um sinal em direção do Sobrado.

- É pr'aquela gente achar o que perdeu. (VERISSIMO, 1963, p.611)

Na Praia do Bispo, em AvóDezanove, há uma excitação crescente por conta da construção do 'foguetão' e existem boatos de que a população local será retirada do bairro e realocada pelo governo, e que suas casas serão destruídas por explosões. Enquanto o mausoléu de Agostinho Neto é projetado para ser uma mansarda da memória angolana, os planos de construção desta morada do passado prevêem a destruição de uma comunidade que também representa um lugar da memória. O 'foguetão', enquanto monumento é um uma forma política de recordação, porém trata-se uma forma de recordação oficial, que será lida pelo "passado que investiga", ao passo que a comunidade local, com suas casas, suas estórias, tradições e mitos, é o "passado que recorda" que será varrido da memória de Luanda se os planos para a inauguração do monumento forem levados a cabo.

Já identificamos que tanto no Sobrado dos Terra - Cambará, quanto na Praia do Bispo, existem as guardiãs da memória não oficial, as matriarcas que observam os movimentos da vida e da morte. Parafraseando Regina Zilberman, na mitologia fundamental de $O$ Continente há uma fórmula de repetição do mito fundador que esquematiza um padrão seqüencial de papéis: Ao pai é dado o papel da conquista, à mãe o da conservação ${ }^{17}$. Tomando emprestado de Zilberman apenas a idéia do padrão seqüencial de papéis ${ }^{18}$, se transpusermos aqui o lugar do pai para o lugar do homem, e o da mãe para o da mulher, teremos que ao homem é dado o

\footnotetext{
${ }^{15}$ O CONTINENTE. Primeiro tomo, p.73.

${ }^{16}$ O CONTINENTE. Primeiro tomo, p. 72.

${ }^{17}$ ZILBERMAN, Regina. "O Continente": do mito ao romance. In: CHAVES, Flavio Loureiro (Org.). $O$ contador de histórias: 40 anos de vida literária de Erico Veríssimo. Porto Alegre: Editora Globo, 1972, p. 176 193.

${ }^{18}$ Destaco do ensaio de Zilberman apenas esta idéia para adequá-la e usá-la como inspiração para uma premissa de uma equação bem diferente da original. A tese que a pesquisadora defende em seu ensaio é bastante específica e distinta do que pretendo fazer. Não há, portanto nenhuma intenção de distorcer o argumento original, nem ingênua, nem propositadamente.
} 
papel da conquista e à mulher o da conservação. AvóCatarina, que não vive mais na casa da AvóNhé, e entretanto aparece e participa na estória contada pelo narrador-menino como se realmente morasse ali, permanece na casa da Praia do Bispo até a proximidade dos trágicos eventos que começam como boatos e logo são confirmados pelos soviéticos: As casas e as famílias da Praia do Bispo serão de fato destruídas e retiradas de lá. Se a casa é o espaço da essência íntima e completa, como quer Tutikian, e as casas da Praia do Bispo serão destruídas, a essência daquelas famílias também o será, juntamente com suas estórias, suas tradições, seus mitos e seus futuros possíveis: Juntamente com sua memória! Quando se anuncia a proximidade do evento trágico para as famílias da Praia do Bispo, AvóCatarina - a guardiã etérea que vive numa espécie de vórtice sustentáculo dos limites entre a vida e a morte - vai embora. A destruição das casas da Praia do Bispo simboliza a morte desta comunidade e de sua memória, e não há mais justificativa para a presença da avó de 'entre dois mundos', pois um deles se extinguirá, restando apenas o outro, o do mausoléu, o da memória oficial. Sem razão de existir, sem tradição a conservar, AvóCatarina desaparece:

- AvóCatarina? - as palavras me saíram dos lábios devagarinho, e não houve resposta.

Nunca mais houve resposta. Não me disse adeus, nem me avisou que já não podia mais falar comigo, nem que fosse às escondidas sem eu dizer a ninguém. (ONDJAKI, 2009, 143)

Quando não há mais a tradição a ser conservada pelas matriarcas da família, entra em cena o papel do homem enquanto conquistador. No caso do narrador de AvóDezanove, a conquista é impulsionada pela inconformidade em relação ao evento que se anuncia, e o menino e seu melhor amigo apelidado de “3,14”, resolvem que eles mesmos sairão em uma missão de conquista, a missão de destruir a obra do mausoléu a fim de impedir que a mesma desencadeie a destruição de suas casas. Como às mulheres é dado o papel de conservar, e aos homens o de conquistar, os meninos saem em uma aventura que visa à reconquista do espaço - físico e simbólico - que depois de recuperado ficará novamente aos cuidados dos moradores da Praia do Bispo. No final do romance, sabemos que a destruição do mausoléu há muito havia sido planejada por um dos soviéticos que também amava a Praia do Bispo e suas famílias e tradições. Reafirmando o papel do homem no sentido da conquista, o camarada Bilhardov desafia o establishment que ele próprio representa em defesa da comunidade que ele aprendeu a amar e que abriga a mulher que ele timidamente cortejava, AvóAgnette, para a qual deixa uma carta que ela nunca chegará a ler: “ Descólpe se faz problem explosón da Masuléu, mas família Dona Nhéte ganha tempo e eles começa obra novamente”(2009, p.177). Bilhardov ainda faz questão de dizer na carta que o "corpe de camarád presidente Agostín 
Neto está bem, salvo de explosón." ${ }^{19}$, afirmando assim sua preocupação com a preservação da memória da comunidade da Praia do Bispo e também da memória nacional angolana. Durante a explosão que ilumina a Praia do Bispo com um espetáculo de luzes e cores, o narrador observa que AvóNhéte permanece na varanda a conversar com seu médico. O papel da matriarca está novamente assegurado, pois permanecendo a Praia do Bispo permanece a responsabilidade da conservação da tradição e memória daquelas famílias.

Em O tempo e o vento há um episódio em que os meninos Rodrigo e Toríbio saem em uma aventura de conquista. Na primeira parte de O RETRATO, Toríbio, um ávido leitor de romances de aventura, é surpreendido por Maria Valéria lendo escondido após a dinda haver ordenado que apagassem o lampião. Maria Valéria conserva a ordem, e Toríbio há de fazer o papel daquele que em vez de conservar, quer conquistar. Maria Valéria ordena que apaguem o lampião e confisca as velas que Toríbio esconde embaixo do colchão. Inconformado, Toríbio convence o irmão mais novo a irem até o cemitério roubar velas das sepulturas, o que acabam fazendo com sucesso e sem que a dinda descubra. Anos mais tarde, homens feitos, Toríbio e Rodrigo viverão realmente o papel de conquistadores ao partirem para a guerra e trazerem mais glória, ou poder, ou prestígio para o Sobrado. Maria Valéria permanecerá na casa, a esperar e cuidar da ordem e conservação do Sobrado que representa a própria história do clã, a mesma história que só se perpetua graças ao papel dado às mulheres, o de conservação da tradição e memória, a mesma memória que, resgatada por Floriano, será a matriz responsável pela gênese de $O$ tempo e o vento:

Quando os viu deitados, Maria Valéria, parada no meio do quarto, de vela acesa na mão, olhou em torno para ver se estava tudo em ordem ${ }^{20}$.

- Agora durmam. (VERISSIMO, 1963, p.67) ${ }^{21}$

Maria Valéria, a guardiã da casa, da tradição e da ordem, assim como AvóCatarina, também conhece os portais da morte e reconhece os passos de quem os atravessa. Na noite da morte do Dr. Rodrigo, o último representante mítico da dinastia dos Terra - Cambará ${ }^{22}$, seu filho Floriano acorda agitado por um sonho pressago no qual um estranho adentra a casa furtivamente. Floriano sai do quarto assustado e encontra a velha Maria Valéria, já cega, do lado de fora:

- Quem é? - sussurrou ela.

\footnotetext{
19 Ibid.

${ }^{20}$ Grifo meu.

${ }^{21}$ O RETRATO. Primeiro tomo.

22 “- Com o Dr. Rodrigo não morre apenas um homem. Acaba-se uma estirpe.”. O ARQUIPÉLAGO, Terceiro tomo, p.1005
} 
A luz da vela projetava-lhe nas faces sombras que a escavavam ainda mais.

- Sou eu, o Floriano.

- Você também ouviu?

- Ouviu o que?

- Uma pessoa entrar... (VERISSIMO, 1963, p.992) 23

Mais tarde, depois de constatada a morte de Rodrigo, o médico da família fala sobre a matriarca:

\begin{abstract}
-Ah! Essa é um rochedo. Auscultei-a há pouco. Que coração! Não te preocupes com ela. - Fez uma pausa, acendeu um cigarro e depois acrescentou: - Desde que o corpo do Dr. Rodrigo saiu de casa, a velha tem andado de um lado para o outro, como quem procura alguma coisa. Sabes o que ela me disse? Que não se surpreendeu com a morte do sobrinho porque sentiu quando a Magra entrou no Sobrado. Perguntei: "Como, D. Maria Valéria?" E ela: "Tenho vivido tanto, que já conheço a morte até pelo cheiro." (VERISSIMO, 1963, 995) ${ }^{24}$
\end{abstract}

Com a morte de Rodrigo, sendo ele o último representante mítico do clã, o Sobrado perde a figura masculina responsável pela conquista. Sem conquistas, não há o que edificar, sem edificar, não resta o que conservar. Sem o que conservar, não há mais o papel da matriarca. Maria Valéria anda de um lado para o outro a procura do passado, porque o futuro dos Terra - Cambará tais quais eles sempre foram segundo a tradição fundada no mito, deixou de existir com a morte de Rodrigo. Se não há o passado, que Maria Valéria procura andando de um lado para o outro, não há memória, se não há memória, já não há futuro.

Os conceitos e desdobramentos teóricos relativos à memória, tradição, mito e rituais tratados neste artigo, dizem respeito diretamente às questões concernentes à identidade. Estas mulheres que são as 'guardiãs', 'cuidadoras', ou quaisquer adjetivos que as qualifiquem como responsáveis pela conservação da memória de uma família ou comunidade são responsáveis em última instância pela conservação da identidade dessas famílias e/ou comunidades. $\mathrm{Na}$ medida em que é passado de geração para geração através da memória que é conservada e enriquecida na tradição, o "passado que recorda" permanece vivo no imprescindível papel de preparar o futuro e não deixar que a morte desintegre esta mesma memória que é fundada nos laços da memória coletiva:

[...]-Avó?

- Diz, meu querido.

- Gosto muito de ti - a Avó não falou nada e continuou a andar, mas apertou minha mãe devagarinho. - Gosto muito das nossas conversas mesmo quando às vezes nem conseguimos dizer nada.

- És um amor. E quando cresceres - ela baixou para falar comigo, olhou - me nos meus olhos com um olhar quieto - quando cresceres, tens que te lembrar de todas estas estórias. Dentro de ti. Prometes? (ONDJAKI, 2009, p.82)

\footnotetext{
${ }^{23}$ O ARQUIPÉLAGO. Terceiro tomo.

${ }^{24}$ Ibid.
} 


\section{Referências}

ASSMANN, Jan. Moses the Egiptian - The Memory of Egypt in Western Monotheism. London: Harvard University Press, 1998.

ASSMANN, Jan. Religión y memoria cultural - Diez estudios. Trad. de Marcelo G. Burello e Karen Saban. Buenos Ayres: Lilmod, Libros de la Araucaria, 2008.

BORDINI, Maria da Glória (Org.). A liberdade de escrever: entrevistas sobre literatura e política. Porto Alegre: Editora da Universidade / UFRGS / Edipucrs, Prefeitura Municipal de Porto Alegre, (Coleção Engenho e Arte; 4), 1997.

CHAVES, Flávio Loureiro (Org.). O contador de histórias - 40 anos de vida literária de Erico Verissimo. Porto Alegre: Editora Globo, 1972.

ONDJAKI. AvóDezanove e o segredo do soviético. São Paulo: Companhia das Letras, 2009.

REMÉDIOS, Maria Luíza Ritzel; SILVEIRA, Regina da Costa (Org.). Redes e Capulanas: identidade, cultura e história nas literaturas lusófonas. Porto Alegre: Editora UniRitter, 2009.

VERISSIMO. Erico. O tempo e o vento. Porto Alegre: Editora Globo, 1963. 